\title{
Surgeon-performed sonographic findings in a traumatic trans-anal rectal perforation
}

\author{
Fikri M Abu-Zidan ${ }^{1 *}$, Mohamed I Abusharia ${ }^{2}$ and Katharina Kessler ${ }^{3}$
}

\begin{abstract}
Early diagnosis and active management of trans-anal rectal injuries is essential for a favorable outcome. Intraperitoneal free air (IFA) is usually diagnosed by an erect Chest X-ray. Point-of-care ultrasound has been recently used to detect IFA. We report a 45-year-old male who presented to the Emergency Department with lower abdominal peritonitis. Surgeon-performed portable point-of-care ultrasound as an extension of the abdominal examination revealed an inflamed omentum with hypoechoic stranding, thickened non compressible small bowel, and free fluid in the pelvis. A transverse abdominal section of the right upper quadrant showed free intraperitoneal air. Rectal examination revealed a longitudinal rectal tear. Laparotomy has confirmed the sonographic findings. There was a $12 \mathrm{~cm}$ intraperitoneal tear of the anterior wall of the rectum which was necrotic. This case clearly demonstrates that portable point-of-care ultrasound gives very useful detailed information even when performed by a non radiologist. Surgeons should be encouraged to use point-of-care ultrasound after appropriate training.
\end{abstract}

Keywords: Rectal trauma, ultrasound, free intraperitoneal air

\section{Introduction}

Rectal injuries are uncommon. They are mainly caused by penetrating trauma. Early diagnosis and active management of trans-anal rectal injuries is essential for a favorable outcome [1,2]. Intraperitoneal rectal injuries will cause peritonitis, sepsis and even death if not detected early. Intraperitoneal free air (IFA) is usually diagnosed by an erect Chest X-ray [2]. If the erect chest $\mathrm{X}$-ray was normal, then an abdominal CT scan is recommended. Point-of-care ultrasound has been recently used to detect IFA $[3,4]$. Hereby, we report an unusual case of trans-anal rectal injury in which pointof-care ultrasound was of a great help for an early diagnosis.

\section{Case presentation}

A 45-year-old male presented to the Emergency Department complaining of lower abdominal pain and dysuria of two days duration. His blood pressure was 120/80 $\mathrm{mmHg}$, his pulse was 107 beat per minute and his temperature was $36.8^{\circ} \mathrm{C}$. Abdominal examination revealed

\footnotetext{
* Correspondence: fabuzidan@uaeu.ac.ae

${ }^{1}$ Head Trauma Group, Faculty of Medicine and Health Sciences, UAE University, Al-Ain, UAE

Full list of author information is available at the end of the article
}

tenderness and guarding in the lower abdomen. Surgeon-performed portable point-of-care ultrasound as an extension of the abdominal examination was done immediately and revealed an inflamed omentum with hypoechoic stranding in the right upper quadrant (Figure 1A), thickened non compressible small bowel (Figure 1B), and free fluid in the pelvis. A transverse abdominal section of the right upper quadrant showed free intraperitoneal air (Figure 2). Rectal examination revealed a large longitudinal rectal tear $8 \mathrm{~cm}$ from the anal verge with an inflamed floppy mucosa. The patient admitted that he has inserted a glass bottle through his anus two days before, which was associated with sudden lower abdominal pain and a small amount of rectal bleeding. Erect chest X-ray confirmed the presence of air under the diaphragm (Figure 3 ). C-reactive protein was $418 \mathrm{mg} / \mathrm{L}$ (Normal less than $0.7 \mathrm{mg} / \mathrm{L}$ ), serum creatinine was 139 micromol/L (normal less than 107 micro$\mathrm{mol} / \mathrm{l}$ ) and white blood cell count was $13.8 \times 10^{9} / \mathrm{L}$. Arterial blood gas has shown an arterial oxygen tension of $50 \mathrm{mmHg}$ on normal air. Laparotomy has confirmed the sonographic findings with thickened omentum, an edematous small bowel, pelvic abscess, and a $12 \mathrm{~cm}$ intraperitoneal tear of the anterior wall of the rectum which was necrotic (Figure 4). The rectum was dissected 

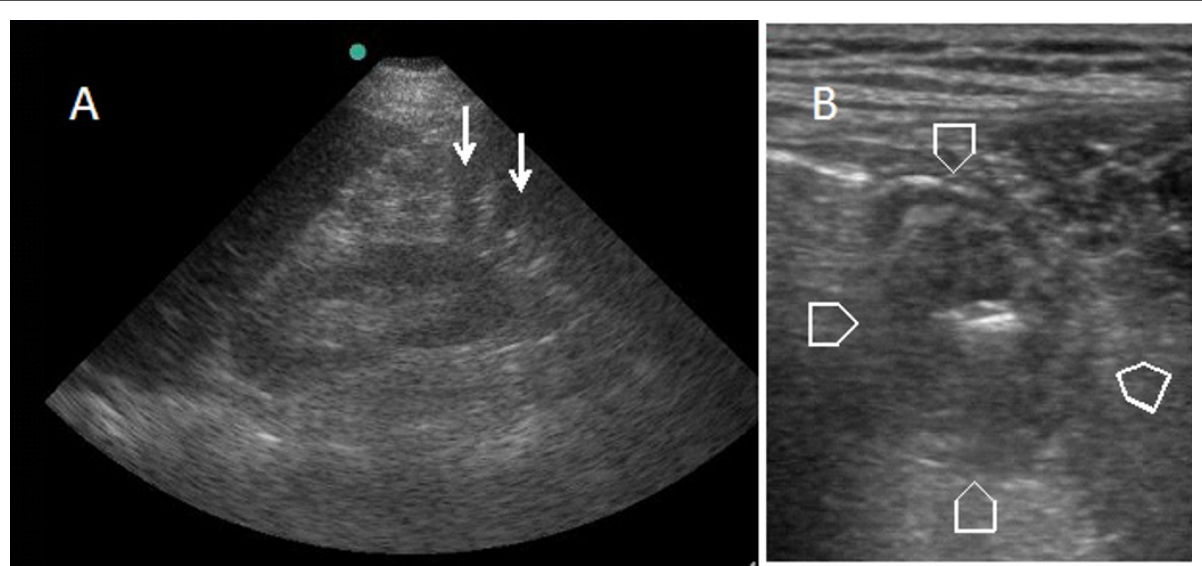

Figure 1 Surgeon-performed bedside ultrasound showing $(A)$ an edematous omentum with hypoechoic stranding in the right upper quadrant of the abdomen (arrows) and (B) a thickened non compressible small bowel in the right lower quadrant of the abdomen (arrow heads).

and transected $8 \mathrm{~cm}$ from the anus. Low mesorectal excision of the necrotic rectum and a Hartman's procedure was performed. Two surgical drains without suction were left in the pelvis. Postoperatively, the patient was ventilated in the ICU. His arterial oxygen tension was $80 \mathrm{mmHg}$ using an oxygen concentration of $50 \%$. The patient received Tazocine intravenously 4.5 gms 8 hourly and Clexane $40 \mathrm{mg}$ subcutaneously daily for one week. His respiratory and renal functions became normal within 4 days. The patient was discharged home on day 10 with good general condition and he is planned for reconnection of the colon after 3 months.

\section{Discussion}

The diagnosis of trans-anal rectal injuries is usually delayed because of patient's denial and late presentation.

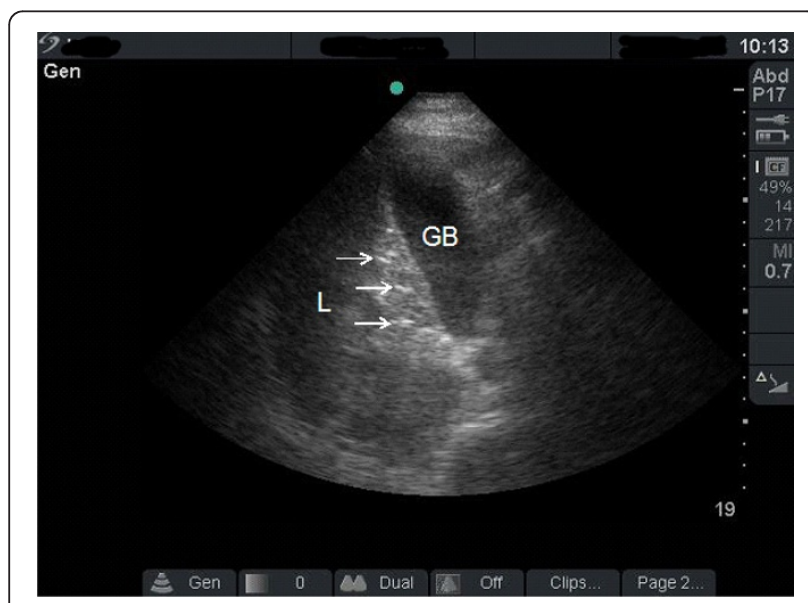

Figure 2 Transverse sonographic section of the right upper quadrant using a curvilinear probe showing hyperdence echogenic small areas (arrows) between the gall bladder (GB) and the liver (L) indicating free air.
Some of these injuries are self inflicted or caused by criminal assault $[1,2]$. High index of suspicion is essential for diagnosis.

In the present patient, portable surgeon-performed point-of-care ultrasound gave very useful information. Point-of-care ultrasound is an extension of the clinical examination. It is a goal-directed study that can be used for rapid diagnosis. It is accurate, non-invasive, cost effective, repeatable, without risk of radiation, and can be done in unstable patients parallel to physical examination and resuscitation $[5,6]$.

It may be argued that ultrasound did not change the clinical management of our present patient. Bedside ultrasound is much quicker when performed by the treating surgeon as an extension of the abdominal examination than doing a formal chest $\mathrm{X}$-ray in the

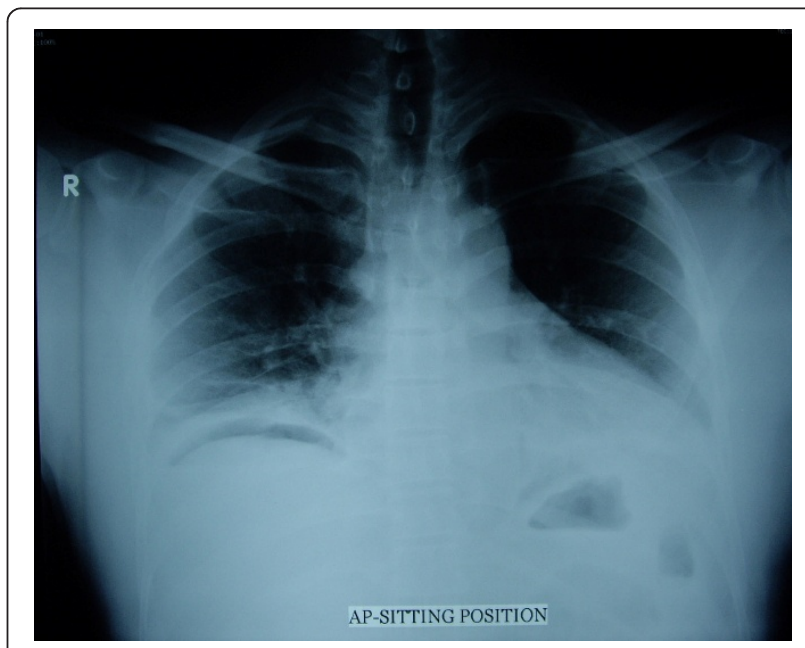

Figure 3 Erect chest X-ray showing free air under the right diaphragm. 


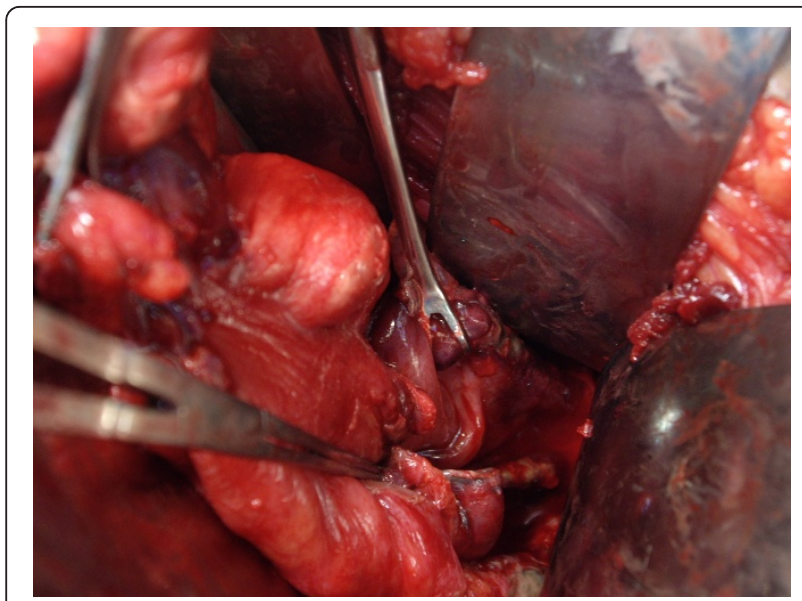

Figure 4 Laparotomy showing a $12 \mathrm{~cm}$ necrotic wound of the anterior wall of the rectum.

Radiology Department. Furthermore, ultrasound can be done while the patient is in the supine position, and may detect small amount of free intraperitoneal air compared with an erect chest X-ray which may be negative in up to $10 \%$ of patients with perforated bowel. Small amount of free intraperitoneal air can be detected under the anterior abdominal wall and in Morison's pouch [7]. This would be useful even in early bowel perforation without peritonitis. Furthermore, ultrasound is useful in disaster and austere situations when formal Xrays cannot be performed [8].

The ultrasound image of IFA results from the reverberation artefact of the ultrasound waves which swings between the ultrasound transducer and the highly reflective air. An increased echogenicity of a peritoneal stripe behind the anterior abdominal wall may be present $[3,7,9]$. The position of the stripe will change when changing the patient's position. Similar to our patient, trapped free intraperitoneal air bubbles in a localized fluid collection will give rise to echogenic foci $[4,7]$. The associated findings of thickened omentum and bowel, and free pelvic fluid pointed towards peritonitis in our patient $[3,10]$.

We have performed bedside ultrasound as an extension of the abdominal examination in our patient before performing the rectal examination. Initially the patient denied the history of inserting a foreign body through his anus and he was diagnosed as having lower urinary tract infection in the Emergency Department. He was suspected to have bowel perforation only after the bedside ultrasound was performed.

It is important to stress that ultrasound usually rules in and does not rule out a bowel perforation which indicates that a negative study does not exclude a bowel perforation. FIA detection is operator dependable and can be difficult even for an experienced ultrasound operator $[11,12]$. The ultrasound findings should be correlated with the clinical picture as a whole and used within defined diagnostic algorithms. If needed, and if the patient was haemodynamically stable, then an abdominal CT scan may give more information than ultrasound [13,14].

It may also be argued that laparotomy would have reached the diagnosis in our patient any way. There are different decisions to be made in cases of peritonitis including the indication for laparotomy and its timing. It would be also useful to collect information about the cause and site of perforation if possible as this may help to decide on what incision to use. Ultrasound may occasionally diagnose the cause of peritonitis, like a perforated duodenal ulcer [4,15].

Early diagnosis and active treatment results in a good prognosis. The good outcome of our patient, despite his multi-organ failure, occurred possibly because of his young age, and active surgical critical care management.

\section{Consent}

Written informed consent was obtained from the patient for publication of his clinical details and accompanying images.

\section{Author details}

${ }^{1}$ Head Trauma Group, Faculty of Medicine and Health Sciences, UAE University, Al-Ain, UAE. ${ }^{2}$ General Surgeon, Al-Ain Hospital, Al-Ain, UAE. ${ }^{3}$ Visceral, and Proctology Surgeon, Al-Ain Hospital, Al-Ain, UAE.

\section{Authors' contributions}

FA operated on the patient, had the idea, and assured the quality of data collected, drafted the paper, repeatedly edited it, and approved its final version. MA assisted in the operation and follow-up of the patient, helped in the idea, and approved the final version of the manuscript. KK operated on the patient, helped in the idea and drafting of the paper, and approved the final version of the manuscript.

\section{Competing interests}

The authors declare that they have no competing interests.

Received: 21 June 2011 Accepted: 12 August 2011

Published: 12 August 2011

\section{References}

1. Orr CJ, Clark MA, Hawley DA, et al: Fatal anorectal injuries: A series of four cases. Journal of Forensic Sciences 1995, 40:219-22.

2. El-Ashaal Yl, Al-Olama A-K, Abu-Zidan FM: Trans-anal rectal injuries. Singapore Med J 2008, 49:54-6.

3. Blaivas M, Kirkpatrick AW, Rodriguez-Galvez M, Ball CG: Sonographic depiction of intraperitoneal free air. J Trauma 2009, 67:675.

4. Patel SV, Gopichandran TD: Ultrasound evidence of gas in the fissure for ligamentum teres: a sign of perforated duodenal ulcer. Br J Radiol 1999, 72:901-2.

5. Abu-Zidan FM, al-Zayat I, Sheikh M, Mousa I, Behbehani A: Role of ultrasonography in blunt abdominal trauma, a prospective study. Eur $J$ Surg 1996, 162:361-365.

6. Abu-Zidan FM, Freeman P, Diku Mandivia: The first Australasian workshop on bedside ultrasound in the Emergency Department. NZ Med J 1999, 112:322-324. 
7. Hefny AF, Abu-Zidan FM: Sonographic diagnosis of intraperitoneal free air. J Emerg Trauma Shock.

8. Dittrich K, Abu-Zidan FM: Role of Ultrasound in Mass-Casualty Situations. International Journal of Disaster Medicine 2004, 2:18-23.

9. Pattison P, Jeffrey RB Jr, Mindelzun RE, Sommer FG: Sonography of intraabdominal gas collections. AJR Am J Roentgenol 1997, 169:1559-64.

10. Lee DH, Lim JH, Ko YT, Yoon Y: Sonographic detection of pneumoperitoneum in patients with acute abdomen. AJR Am J Roentgenol 1990, 154:107-9.

11. Chen SC, Wang HP, Chen WJ, Lin FY, Hsu CY, Chang KJ, et al: Selective use of ultrasonography for the detection of pneumoperitoneum. Acad Emerg Med 2002, 9:643-5.

12. Chadha D, Kedar RP, Malde HM: Sonographic detection of pneumoperitoneum: An experimental and clinical study. Australas Radiol 1993, 37:182-5.

13. Radwan MM, Abu-Zidan FM: Focussed Assessment Sonography for Trauma (FAST) and CT scan in blunt abdominal trauma: surgeon's perspective. Afr Health Sci 2006, 6:187-90.

14. Abu-Zidan FM, Sheikh M, Jaddallah F, Windsor JA: Blunt abdominal trauma: Comparison of ultrasonography and computed tomography. Austral Radiol 1999, 43:440-3.

15. García Santos JM: Direct sonographic signs of acute duodenal ulcer. Abdom Imaging 1999, 24:226-7.

doi:10.1186/1749-7922-6-26

Cite this article as: Abu-Zidan et al: Surgeon-performed sonographic findings in a traumatic trans-anal rectal perforation. World Journal of Emergency Surgery 2011 6:26.

\section{Submit your next manuscript to BioMed Central} and take full advantage of:

- Convenient online submission

- Thorough peer review

- No space constraints or color figure charges

- Immediate publication on acceptance

- Inclusion in PubMed, CAS, Scopus and Google Scholar

- Research which is freely available for redistribution

Submit your manuscript at www.biomedcentral.com/submit
Biomed Central 